\title{
TENDENCIAS SOBRE LA OBSERVANCIA Y LA VIOLACIÓN DE LOS DERECHOS HUMANOS EN MÉXICO, 1996-2000
}

\section{Orlane DEGRELLE*}

RESUMEN: La autora analiza las tendencias en la observancia de los derechos humanos en México de 1996 a 2000 desde cuatro puntos de vista: el nivel gubernamental (Comisión Nacional de Derechos Humanos), la perspectiva de una organización no gubernamental (Centro de Derechos Humanos "Fray Francisco de Vitoria"), la perspectiva intergubernamental (Comisión Interamericana y de Naciones Unidas de Derechos Humanos), y el trabajo de Amnesty International y Human Rights Watch. Las principales violaciones en los reportes de estos cuerpos involucran los siguientes derechos individuales: derecho a defender los derechos humanos, a la vida, a la libertad personal a la integridad física y psicológica, libertad de opinión, expresión e información, a la seguridad jurídica y derechos de la mujer. Respecto de los derechos colectivos, la autora toca los derechos de los pueblos indígenas y se refiere de modo general a los derechos económicos sociales y culturales. La autora concluye que las principales violaciones involucran la actividad de las fuerzas públicas y la impunidad.

ABSTRACT: The author analyses the tendencies in human rights enforcement in Mexico from 1996 to 2000 in a four sided perspective: the governmental level (National Human Rights Commission), the non-governmental organization perspective (Centro de Derechos Humanos "Fray Francisco de Vitoria"), the intergovernmental perspective (Inter-American and United Nations Commission on Human Rights) and the work of Amnesty International and Human Rights Watch. The main violations in the reports by these bodies concern the following individual human rights: right to defend human rights, life, personal freedom, physical and psychological integrity, freedom of opinion, expression and information, political rights, legal security and women's rights. As regards collective rights the author compared indigenous peoples' rights, and reference is made generally to economic, social and cultural rights. The author concludes that main violations are derived from the activity of public forces and impunity.

RESUMÉ: L'auteur analyse les tendances dans l'application des droits de l'homme au Mexique de 1996 à 2000 de quatre points de vue: le niveau gouvernemental (Commission Nationale des Droits de l'Homme), la perspective d'une organisation non-gouvernementale (Centro de Derechos Humanos "Fray Francisco de Vitoria"), la perspective intergouvernementale (Commission Interaméricaine et des Nations Unies des Droits de l'Homme); et le travail d'Amnistie Internationale et Human Rights Watch. Selon les rapports de ces organisations, les principales violations concernent les droits individuels suivants: droit à défendre les droits de l'homme, droit à la vie, à la liberté personnelle, à l'intégrité physique et psychologique, la liberté d'opinion, d'expression et d'information, le droit à la sécurité juridique et les droits de la femme. En ce qui concerne les droits collectifs, l'auteur aborde les droits des peuples indigènes et se réfère de manière générale aux droits économiques, sociaux et culturels. L'auteur conclut en soulignant que les principales violations se rapportent à l'activité des forces publiques et à l'impunité. 
SUMARIO: I. Introducción. II. Presentación general y comparación de los organismos y de su trabajo. III. Violaciones de los derechos humanos denunciadas en los informes. IV. Conclusiones generales relativas a la postura de los organismos. V. Conclusiones generales relativas a la evolución de los derechos humanos en México entre 1996 y 2000.

\section{INTRODUCCIÓN}

La idea de investigar y de intentar medir la evolución de la situación de los derechos humanos en México, surgió de la comprobación de que, a pesar que éstos se volvieron uno de los temas centrales de la vida política mexicana desde los años ochenta, no existía un análisis comparativo de los principales informes de instituciones públicas y privadas sobre el tema. Así, realizar éste intento podía dar luces sobre dicha situación.

Para realizar el estudio, había que encontrar fuentes de información confiables, definir criterios de objetividad, y delimitar en el tiempo el periodo a estudiar, para que fuera factible el proyecto. ${ }^{1}$ En cuanto a las fuentes, elegí analizar informes de varios organismos de derechos humanos, por ser los principales generadores de datos sobre el tema. Para conseguir objetividad en el trabajo, decidí basar la metodología para el análisis de estos informes, cruzando cuatro niveles diferentes, con el propósito de tener la visión más amplia posible de la situación, pero también de comparar los diferentes enfoques y los métodos de recopilación de información, y de explicar las diferencias y las similitudes entre las conclusiones emitidas. Los cuatros niveles de análisis elegidos fueron: 1) el nivel gubernamental nacional, con los informes de la Comisión Nacional de Derechos Humanos; 2) el nivel no gubernamental nacional, con los informes del Centro de Derechos Humanos "Fray Francisco de Vitoria"; 3) el nivel gubernamental internacional, con los informes de la Comisión Interamericana de los Derechos Humanos y de la Organización de Naciones Unidas; y 4) el nivel no gubernamental internacional, con los informes de Amnistía Internacional y de Human Rights Watch. En cuanto al periodo a analizar, elegí una época de cinco años, lo que me pareció razonable para

1 Ya que varias características del país contribuyeron a la complejidad del proyecto: la superficie; las diferencias de comportamiento de las autoridades, según se trate de federales, estatales o de municipales; las de los distintos partidos, de las áreas urbanas, semi urbanas o rurales, etcétera. 
asegurar la factibilidad del estudio. Con el fin de que el trabajo, tuviese un mayor valor heurístico, decidí concentrarme en el periodo que va del año 1996 al año 2000, porque así se podía tener una visión de la evolución reciente de la situación de los derechos humanos en México.

\section{PRESENTACIÓN GENERAL Y COMPARACIÓN}

\section{DE LOS ORGANISMOS Y DE SU TRABAJO}

La Comisión Nacional de Derechos Humanos (CNDH) es un organismo con carácter gubernamental. Fue creado en abril de 1990 por el gobierno mexicano, con el objetivo de supervisar y de mejorar el respeto de los derechos humanos en el país. La CNDH publica informes anuales sobre sus actividades, en los cuales presenta las diferentes acciones que realiza cada año, ${ }^{2}$ pero no realiza un diagnóstico de la evolución de los derechos humanos en el país. Sin embargo, tal evolución se puede deducir de las cifras presentadas en los anexos al informe, donde se encuentra una lista de las quejas recibidas por la $\mathrm{CNDH}$ durante el periodo anual, las violaciones de derechos humanos más denunciadas, y las supuestas autoridades responsables de estas violaciones. ${ }^{3}$ A partir de eso, y por interpretación, se puede tener una idea de la evolución de la situación de los derechos humanos en México. Se destaca al mismo tiempo que la principal razón de ser de tal organismo gubernamental es defender el respeto de los derechos humanos, y tiene también facultad para denunciar las violaciones. El trabajo de la CNDH es en sí mismo parte del proceso de mejoramiento de la situación de los derechos humanos en México, y no consiste únicamente en un trabajo de observación de la situación de los derechos de la persona humana. ${ }^{4}$

2 Aquí se trata, por ejemplo, del programa de recepción de quejas, del programa de emisión de recomendaciones, del programa de inconformidades, del programa de lucha contra la impunidad, del programa para la mujer, el niño y la familia, del programa para daños causados a periodistas y defensores civiles de derechos humanos, del programa especial para los desaparecidos, etcétera. Véase: Comisión Nacional de Derechos Humanos, Informe de actividades, noviembre de 1999-noviembre de 2000, México, 2001, 225 pp.

3 Aquí, en cuanto a las denuncias más frecuentes de violaciones de derechos humanos y a las autoridades responsables, nos limitemos al análisis de los diez primeros, por una cuestión práctica de factibilidad y de tiempo.

4 Se podría tener una mejor idea de la evolución de la situación de los derechos humanos en México a través del análisis de las recomendaciones y de los programas de la $\mathrm{CNDH}$ - que reflejan un trabajo enorme por parte del organismo- pero tal finalidad escapó a los objetivos de este trabajo. 
Elegí al Centro de Derechos Humanos "Fray Francisco de Vitoria" (CDH"FFV") como organización mexicana de defensa de los derechos humanos representativa del nivel no gubernamental en México. Este organismo presentaba informes anuales sobre derechos humanos en México desde 1989. Sin embargo, el que analicé fue el último que publicó la organización por falta de recursos financieros. ${ }^{5}$ Por ello, el análisis del nivel no gubernamental nacional está basado únicamente en este informe. Sin embargo, es amplio y contiene información detallada sobre nueve tipos de derechos humanos diferentes. ${ }^{6}$ Las fuentes usadas para la elaboración del informe se basan en casos directamente relatados por las víctimas o sus familias, casos registrados por otras ONGs, o también información proveniente de periódicos y revistas nacionales. El objetivo del informe, según el CDH"FFV", era permitir al lector enterarse de la situación de los derechos humanos en México, y también de advertir si había un mejoramiento de la misma.

La Comisión Interamericana de los Derechos Humanos (CIDH) es una de las dos entidades del sistema interamericano de protección y de promoción de los derechos humanos. Fue creada en 1959 y tiene su sede en Washington; el otro organismo es la Corte Interamericana de Derechos Humanos, que fue creada en 1969 y que tiene su sede en San José, Costa Rica. La CIDH es un organismo autónomo de la Organización de los Estados Americanos (OEA). Actúa en representación de todos los países de la OEA, y se compone de siete miembros independientes elegidos por la Asamblea General. Funciona de manera permanente y se reúne en sesiones ordinarias y extraordinarias varias veces cada año. Desde 1961, la CIDH efectúa visitas in loco en los países miembros de la OEA para observar la situación de los derechos humanos y publicar informes especiales. ${ }^{7}$ Desde 1965, recibe quejas relativas a casos individuales de violación de derechos humanos. En el caso de México, la CIDH ha realizado un

5 No logré encontrar los informes sobre 1996 y 1997 por una razón práctica, vinculada a problemas de reestructuración de la organización. La referencia del que sí analicé es la siguiente: Centro de Derechos Humanos "Fr. Francisco de Vitoria O. P.", A. C., Informe anual: La situación de los derechos humanos en México, noviembre 1997-octubre 1998, México, 1998, 96 pp.

6 Estos derechos son: el derecho a defender los derechos humanos, el derecho a la vida, el derecho a la libertad personal, el derecho a la integridad física y psicológica, los derechos de los pueblos indígenas, el derecho a la libertad de opinión, de expresión y de información, los derechos políticos, y el derecho a la seguridad jurídica.

7 México es miembro de la OEA desde 1948, ya que fue uno de los Estados fundadores de la organización. 
solo informe, pero es muy amplio y muy detallado. ${ }^{8}$ Se hizo a partir de la documentación y de la información recibida antes, durante y después de una visita in loco realizada en México del 15 al 24 de julio de 1996, en razón de una invitación del gobierno mexicano. Esta visita fue la primera a México, y consecuentemente el informe es el primero que publicó la CIDH sobre derechos humanos en el país. Las fuentes que se usaron para elaborarlo provienen del gobierno mexicano y de ONGs.

La Organización de Naciones Unidas (ONU) es un organismo intergubernamental. El alto comisionado para los Derechos Humanos es su representante oficial para los asuntos relativos a los derechos humanos. ${ }^{9}$ Depende directamente del secretario general de Naciones Unidas, y actúa en el marco de la autoridad y de las decisiones de la Asamblea General, del Consejo Económico y Social y de la Comisión de los Derechos Humanos. Lo nombra el secretario general, con el acuerdo de la Asamblea General, para cubrir un mandato de cuatro años. Su responsabilidad radica en la protección de los derechos humanos, el apoyo a los Estados en materia de derechos humanos, la enseñanza en esta materia, el diálogo con los gobiernos, la cooperación internacional y la consolidación del sistema de Naciones Unidas en la esfera de derechos humanos. Entre 1996 y 2000, se publicaron varios documentos en el marco de las actividades del alto comisionado de Naciones Unidas relativos a México: decisiones, avisos, informes, exposiciones escritas, etcétera. Pero no existe ningún informe anual sobre la situación general de los derechos humanos en México. Así que, frente a estas fuentes heterogéneas, elegí analizar algunos informes de relatores especiales ${ }^{10} \mathrm{o}$ de subcomisiones sobre temas específicos importantes para México. Estos informes consisten en un intercambio de informaciones entre México y los relatores de Naciones Unidas. Se elaboran generalmente después de una visita in loco al país, y utilizan infor-

8 El informe analiza las estructuras del Estado, el derecho a la vida, a la libertad y a la integridad personal. Hace una evaluación de la situación del derecho a la justicia, de los derechos políticos, de los derechos de los pueblos indígenas, de los derechos económicos, sociales y culturales, y de los derechos de la mujer. Contiene un capitulo especial sobre la libertad de expresión —lo que constituye una innovación en comparación con los informes anteriores de la $\mathrm{CIDH}-$. Concluye con las recomendaciones de la CIDH a México.

9 El alto comisionado para los derechos humanos es Mary Robinson, desde 1997.

10 Véase, por ejemplo, el informe: Rapport du Rapporteur Spécial sur les exécutions extrajudiciares, sommaires ou arbitraires: situation dans les pays mis en cause, Conseil Economique et Social, E/CN.4/1997/60/Add.1, 23 décembre 1996. 
maciones de fuentes que provienen del gobierno, de ONGs, del medio académico, y de los propios afectados.

Amnistía Internacional es una ONG internacional de defensa de los derechos humanos. Fue creada en 1961 por el abogado británico Peter Benenson, y funciona sobre la base del respeto de los principios de imparcialidad y de independencia. Tiene secciones nacionales en 56 países. Su Secretaría Internacional se encuentra en Londres. Tiene el estatuto consultivo en el Consejo Económico y Social de la ONU, en la UNESCO y en el Consejo de Europa. Coopera también con la Corte Interamericana de los Derechos Humanos de la OEA. Sus informes son anuales y generales, y tratan de la situación de los derechos humanos en varios países. En el caso de México, existe un informe por cada año entre 1996 y 2000. Las fuentes son mayoritariamente indirectas, pero se organizan visitas in loco también. Amnistía Internacional tiene una sección en la ciudad de México.

Para terminar, Human Rights Watch se define ella misma como una organización independiente, no gubernamental, que recibe fondos privados individuales y de fundaciones del mundo entero. Organiza investigaciones sobre violaciones de derechos humanos en más o menos setenta países. Fue creada en 1978, y se encuentra hoy en varias partes del mundo. ${ }^{11}$ Publica informes anuales, y existen, como en el caso de Amnistía Internacional, informes sobre México de 1996 hasta 2000. Los informes se hicieron a partir de investigaciones efectuadas directamente por representantes de la organización, y dan informaciones sobre casos precisos. No se limita — como en el caso de Chiapas, por ejemplo - a presentar las violaciones de derechos humanos cometidas por el gobierno mexicano, sino también presenta las que cometieron los opositores al régimen, lo que ofrece una mayor apertura. Human Rights Watch no tiene una sección en México pero trabaja con la colaboración de la Liga Mexicana de Defensa de los Derechos Humanos, una ONG mexicana de derechos humanos.

La presentación de los organismos que han publicado los informes que se utilizan para esta investigación muestra la heterogeneidad de su naturaleza, de las metodologías de trabajo y de las fuentes que utilizan, así como del tipo y de la frecuencia de las publicaciones. Por eso, el análisis de las características de cada organismo y de su trabajo conduce a varias hipótesis, según las cuales el resultado final de cada informe puede

11 África, Asia, Medio Oriente, América, y países firmadores de los Acuerdos de Helsinki. 
depender de la sensibilidad del organismo y de su metodología de trabajo. También la calidad o precisión del informe puede depender de los recursos financieros que, por supuesto, son variables. ${ }^{12}$ Así, por ejemplo, una visita in loco permite obtener una información de primera mano, que será más confiable que la información difundida por un medio de comunicación. También, una ONG, por ejemplo, puede tener una postura más crítica por su razón de ser, que radica, en ciertos casos y bajo ciertas circunstancias, en la crítica al Estado y a su actuación frente al problema de los derechos humanos. Estas hipótesis tienen que ser analizadas a través del contenido de los informes mismos, para ver si, comparándolos, se pueden encontrar coincidencias o variaciones en cuanto a los derechos humanos estudiados y en cuanto a las conclusiones emitidas, y sobre todo para ver si se pueden identificar constantes en lo que toca a la evolución de la situación de los derechos humanos en México durante estos últimos años.

\section{VIOLACIONES DE LOS DERECHOS HUMANOS DENUNCIADAS EN LOS INFORMES}

Los problemas más relevantes vinculados a los derechos humanos durante el periodo estudiado, y que he localizado en la lectura de los informes, son principalmente vinculados a violaciones de derechos individuales. Sin embargo, existen también violaciones de derechos colectivos. Así que las dividí en dos grupos.

Las violaciones de los derechos individuales que encontré son los siguientes: las violaciones del derecho a defender los derechos humanos (activistas de derechos humanos, miembros de organizaciones de vocación social), las violaciones del derecho a la vida (con las ejecuciones extrajudiciales y con las masacres de Acteal, El Charco, El Bosque y de Aguas Blancas), las violaciones del derecho a la libertad personal (con las desapariciones forzadas), las violaciones del derecho a la integridad física y psicológica (con la tortura por parte de la policía y del ejercito), las violaciones del derecho a la libertad de opinión, de expresión y de información (periodistas y activistas de derechos humanos), las violaciones de los

12 Por ejemplo, tratando del caso de una organización nacional no gubernamental de derechos humanos, o del caso de una organización internacional gubernamental de derechos humanos, que son dos situaciones extremas en cuanto a la disponibilidad de recursos. 
derechos políticos (elecciones), las violaciones del derecho a la seguridad jurídica, y las violaciones de los derechos de la mujer.

Las violaciones de los derechos colectivos son las siguientes: las violaciones de los derechos de los pueblos indígenas (violencia rural) y las violaciones de los derechos económicos, culturales y sociales.

Aquí presentaré, entonces, cada uno de estos derechos humanos, sus violaciones en México, como las trataron - $\mathrm{O}$ no- los organismos estudiados, y las conclusiones que pueden derivar de la evolución de la situación de cada uno de ellos en el periodo 1996-2000.

\section{Violaciones del derecho a defender los derechos humanos}

Este derecho es importante en un país en proceso de transición a la democracia, porque su grado de respeto permite tener una idea de la apertura política real del gobierno. No aparecieron violaciones de este derecho en los anexos de los informes de la CNDH analizados para este estudio. ${ }^{13} \mathrm{Sin}$ embargo, el CDH"FFV" habló en su informe de un acercamiento positivo entre la CNDH y los organismos civiles, y de la emisión de recomendaciones basadas en instrumentos internacionales de defensa de los derechos humanos, lo que parece positivo. Pero la ONG mexicana aludió también a una situación preocupante de los defensores de los derechos humanos en México, que atrajo la atención de la comunidad internacional, por el hostigamiento, las amenazas y los actos arbitrarios e ilegales, las declaraciones de funcionarios de alto nivel, que tuvieron como consecuencia tensar la situación entre los poderes públicos y las organizaciones civiles. ${ }^{14}$ Fue este punto bastante negativo para el respeto de este derecho durante el periodo analizado.

La CIDH trató la cuestión de la violencia y del hostigamiento en contra de los defensores de los derechos humanos y de los miembros de organizaciones sociales en su capítulo sobre la libertad de expresión. Presentó

13 Comisión Nacional de Derechos Humanos, Informe de actividades, mayo de 1996-mayo de 1997, anexos, México, 1997, 753 pp.; Comisión Nacional de Derechos Humanos, Informe de actividades, enero-diciembre de 1998, anexos, México, 1999, 801 pp.; Comisión Nacional de Derechos Humanos, Informe de actividades, enero-diciembre de 1999, anexos, México, 2000, 689 pp. Nos falta el informe sobre 1997 por razones prácticas. Sin embargo, existen programas de la CNDH relativos a este derecho. El informe sobre 1999, por ejemplo, contiene un Programa de Atención de Agravios a Periodistas y Defensores Civiles de Derechos Humanos. Véase id., Informe de actividades, enerodiciembre de 1999, anexos..., cit., en esta misma nota, pp. 601-603.

14 CDH"FFV", op. cit., nota 5. 
denuncias, casos de violaciones y de expulsiones. Recomendó, en esta época, la adopción de medidas para sancionar las violaciones presentadas y la protección del trabajo de los defensores de los derechos humanos. ${ }^{15}$

El relator especial de la ONU sobre Ejecuciones Extrajudiciales, Sumarias y Arbitrarias, en su informe de 1996, habló, en el caso de México, de los defensores de los derechos humanos como principales víctimas de amenazas al derecho a la vida. Así, el alto comisionado para los derechos humanos de la ONU expresó su preocupación en cuanto a la multiplicación de las quejas vinculadas a éstas amenazas. Subrayo los esfuerzos de la CNDH en este marco, pero lamentó la ausencia de aplicación de las recomendaciones de esta última. ${ }^{16}$ En un informe publicado en 1997, el relator especial reiteró el problema de las amenazas dirigidas a defensores de derechos humanos y dirigentes de organizaciones autóctonas, y pidió la protección de varias personas. ${ }^{17}$ Finalmente, en un informe de 1999, se refirió a una situación de amenazas de muerte en contra de defensores de derechos humanos y miembros de ONGs, sobre todo en las zonas rurales y aisladas del país. ${ }^{18}$

Amnistía Internacional, por su parte, presentó las agresiones en contra de los defensores de derechos humanos como uno de los principales problemas vinculados a la situación de los derechos de la persona humana en México, y dio algunos ejemplos de violaciones en los Estados de Oaxaca, Guerrero y Chiapas. ${ }^{19}$ Sucedió lo mismo con el informe sobre 1997, además del problema de la expulsión de unos activistas extranjeros de defensa de derechos humanos. ${ }^{20} \mathrm{El}$ informe de 1997 abordó casos de detenciones arbitrarias y de amenazas de muerte en contra de defensores de derechos humanos y de otras expulsiones. ${ }^{21}$ El último informe analizado,

15 Comisión Interamericana de Derechos Humanos-Organización de los Estados Americanos, Informe sobre la situación de los derechos humanos en México, 1998, http://www.cidh.oas.org/contryrep/Mexico98sp/indice.htm.

16 Rapport..., cit., nota 10.

17 Ibidem, 19 de diciembre de 1997.

18 Exécutions extrajudiciaires, sommaires ou arbitraires-Mission au Mexique, Conseil Economique et Social, E/CN.4/2000/3/Add.3, 25 novembre 1999/Droits civils et politiques, Rapport du Rapporteur spécial, Mme Asma Jahangir, présenté conformément à la résolution 1999/35 de la Commission.

19 Amnistía Internacional, Informe 1997, Londres, Amnistía Internacional, Publicaciones, 1997, pp. 275-279.

20 Amnistía Internacional, Informe 1998, Londres, Amnistía Internacional, Publicaciones, 1998, pp. 249-252.

21 Amnistía Internacional, Informe 1999, Londres, Amnistía Internacional, Publicaciones, 1999, pp. 304-307. 
sobre 1999, trató casos de secuestros y de amenazas de muerte, con el ejemplo de los miembros del Centro Miguel Agustín Pro Juárez, ${ }^{22}$ y recomendaciones de Naciones Unidas sobre el estatuto de los observadores extranjeros en México, que fueron ignoradas por el gobierno mexicano. ${ }^{23}$

Human Rights Watch, en su informe de 1996, mencionó también las agresiones a activistas de derechos humanos y a miembros de ONGs, y calificó el año como malo para los observadores de derechos humanos. ${ }^{24}$ En el informe sobre 1997, aludió a la agresividad por parte del gobierno mexicano contra la supervisión internacional en materia de derechos humanos, en virtud del rechazo de un informe de la misma organización sobre la violencia rural, la expulsión de dos miembros de la Federación Internacional de los Derechos Humanos y de doce europeos que participaron en una manifestación en Chiapas, y las amenazas contra varios organismos de derechos humanos. ${ }^{25}$ Para 1998, relató una persistencia de las agresiones y de las expulsiones de defensores de derechos humanos. Mencionó también un aumento de la presión internacional por medio del cabildeo en Estados Unidos de América y en Europa de organismos mexicanos, y se refirió a una tentativa de división de estos grupos por el gobierno, acompañada de restricciones para la observación internacional. ${ }^{26}$ Para terminar, según el informe sobre la situación en 1999, siguieron las agresiones a defensores de derechos humanos y las presiones sobre los observadores extranjeros. ${ }^{27}$

Se puede comprobar, entonces, la amplitud del problema en cuanto al derecho a defender los derechos humanos en México entre 1996 y 2000. Un aumento de la atención de la comunidad internacional se enfrentó a una apertura lenta del gobierno mexicano, y siguieron las violaciones de este derecho en México. Cada organismo trató la cuestión de la misma manera, y no aparecieron diferencias de puntos de vista, o tampoco una evolución positiva o negativa de la situación de este derecho, aparte del

22 Este centro es una ONG mexicana de derechos humanos.

23 Amnistía Internacional, Informe 2000, Londres, Amnistía Internacional, Publicaciones, 2000, pp. 287-289.

24 Human Rights Watch World Report 1997, Events of 1996, "Mexico", Nueva York, Human Rights Watch, diciembre de 1996, pp. 110-116.

25 Human Rights Watch, Informe Anual, Eventos de 1997, "México", Human Rights Watch, http://www.hrw.org/-spanish/inf_anual/1998/mexico.html.

26 Human Rights Watch World Report 1999, Events of December 1997-November 1998, "Mexico", Nueva York, Human Rights Watch, diciembre de 1998, pp. 131-138.

27 Human Rights Watch World Report 2000, Events of 1999, "Mexico", Human Rights Watch, http//.www.hrw.org/wr2k/americas-07.htm. 
trabajo de la CNDH, que consideraron como positivo el Centro Fray Francisco de Vitoria y los relatores de la ONU. ${ }^{28}$

\section{Violaciones del derecho a la vida}

El derecho a la vida es el más básico y el más esencial de todos los derechos humanos. No aparecieron tampoco violaciones de este derecho en los anexos de los informes de la $\mathrm{CNDH} .{ }^{29}$ Por otro lado, el informe del $\mathrm{CDH}$ "FFV" fue bastante negativo en cuanto a su evolución. Una parte significativa del reporte le estuvo dedicada, y apareció como violado de modo persistente. El número de personas cuya muerte podía presumirse infligida por miembros de las fuerzas de seguridad aumentó en comparación con los años anteriores. Además, según el organismo, apareció un nuevo tipo de violación: en el pasado, las ejecuciones arbitrarias y extrajudiciales tomaban lugar de manera individual y selectiva. Desde entonces, más de tres acontecimientos dieron lugar a la muerte indiscriminada a varias personas (Acteal, El Charco, El Bosque y Aguas Blancas). ${ }^{30}$ El organismo destacó también casos de asesinatos de miembros del PRI en Chiapas. ${ }^{31}$

La CIDH consideró en esa época las violaciones del derecho a la vida como uno de los problemas fundamentales encontrados durante su visita en México. Subrayó el organismo un aumento de los homicidios en ciertas zonas del país, una persistencia de las ejecuciones extrajudiciales y de la impunidad de sus autores. Aparecieron también en el informe ejecuciones de miembros del Partido de la Revolución Democrática (PRD) cometidas por miembros del Partido Revolucionario Institucional (PRI), y numerosos casos que quedaron sin sanciones. No obstante, reconoció la voluntad de la CNDH y de la Procuraduría General del Distrito Federal de atacar estas conductas. Pero, los acontecimientos en Chiapas, y el ejemplo de la masacre del Charco en 1998, en el estado de Guerrero, fueron señalados como puntos negativos para el derecho a la vida en México. ${ }^{32}$

28 Se insiste aquí en que el periodo estudiado es 1996-2000, ya que en el 2001, el nuevo gobierno ha adoptado medidas a favor de la supervisión internacional.

29 CNDH, op. cit., nota 13, p. 7.

30 Este punto es criticable en lo que, en México, las ejecuciones extrajudiciales han siempre existido.

31 CDH“FFV", op. cit., nota 5, p. 7.

32 CIDH-OEA, op. cit., nota 15, p. 7. 
La ONU, con el Informe del Relator Especial sobre Ejecuciones Extrajudiciales, Sumarias y Arbitrarias de 1996, presentó numerosas denuncias de violaciones del derecho a la vida en este año -incluso habló del doble, en comparación con 1995-. Las víctimas fueron defensores de los derechos humanos, periodistas, dirigentes de organismos campesinos y autóctonos miembros de partidos políticos y de comunidades religiosas..$^{33}$ En el informe de 1999, el relator especial enfocó su trabajo de investigación - efectuó una visita en México del 12 al 24 de julio- ${ }^{34}$ sobre los acontecimientos de Acteal, El Bosque, Aguas Blancas, El Charco y Ciudad Juárez. ${ }^{35}$ Se concentró en las medidas tomadas por el gobierno para proteger el derecho a la vida, en la proporcionalidad y la oportunidad del recurso a la fuerza por parte de los encargados de hacer aplicar la ley, en la confiabilidad de las investigaciones, en las medidas tomadas para el juicio de los autores de ejecuciones, para impedir que los hechos se repi$\tan y$, en fin, en la complicidad de autoridades gubernamentales en las ejecuciones. El relator especial aludió a una "cultura de la violencia" y de la impunidad. En cuanto a Acteal, ${ }^{36}$ El Bosque, ${ }^{37}$ Aguas Blancas, ${ }^{38}$ y El Charco, ${ }^{39}$ que fueron casos de homicidios de grupos de personas, aparecieron problemas tales como la complicidad y la impunidad de los autores responsables de los hechos, y también irregularidades en los procesos de investigación. Surgieron también casos individuales de ejecuciones extrajudiciales, y casos de violaciones del derecho a la vida, cuyos autores no eran miembros del gobierno, sino grupos armados de la oposición o paramilitares. Según el relator especial, era difícil entender bien la si-

33 Op. cit., nota 10, p. 7.

34 La visita in loco consistió en un encuentro con funcionarios y representantes de organismos públicos, en entrevistas con representantes de ONGs y con testigos o familiares de víctimas de ejecuciones extrajudiciales, y en una visita a los estados de Guerrero y de Chiapas, y a Ciudad Juárez.

35 Op. cit., nota 10, 1999, p. 8. Para una descripción detallada de los acontecimientos, véase el informe.

36 La masacre de Acteal tuvo lugar en Chiapas, el 22 de diciembre 1997. La población de este pueblo fue víctima de un ataque por parte de un grupo armado. Las fuerzas de seguridad estatales no hicieron nada para impedirlo, y resultaron varios muertos y heridos. Sobre este acontecimiento se puede consultar el informe de la CNDH 01/98.

37 La masacre del Bosque tuvo lugar en Chiapas, el 10 de junio de 1998, y resultó de un enfrentamiento entre el EZLN y las autoridades. Aquí se puede consultar el informe 74/98 de la CNDH.

38 La masacre de Aguas Blancas tuvo lugar en Guerrero, el 28 de junio de 1995, y resultó de una emboscada de la policía contra un grupo de manifestantes. Véase sobre este acontecimiento el informe 104/95 de la CNDH y el informe 49/97 de la CIDH.

39 La masacre del Charco tuvo lugar en Guerrero, el 7 de junio de 1998, y consistió en un enfrentamiento entre el Ejército Popular Revolucionario (EPR) y el Ejército. 
tuación en este nivel, por la confusión de la información, y la situación "explosiva" en Chiapas. El caso de Ciudad Juárez era un caso especial porque no se pudo saber si los responsables de esta situación de violación del derecho a la vida eran agentes estatales o si eran particulares. ${ }^{40}$ Pero apareció en el informe por su gravedad y por la inactividad de las autoridades en cuanto a los resultados de las investigaciones. El relator especial habló también de casos de homicidios vinculados a las preferencias sexuales de ciertas personas, y de la no-aplicación de la pena de muerte, aunque todavía esta en vigor en México. Así, para terminar, recomendó al gobierno mexicano tomar medidas tales como la desmilitarización de la sociedad y la abolición legal de la pena de muerte.

En cuanto a los informes de Amnistía Internacional, las ejecuciones extrajudiciales y las desapariciones forzadas aparecieron como un elemento central de las violaciones de los derechos humanos en México. El informe de 1996 trató la masacre de Aguas Blancas y la impunidad de sus responsables. ${ }^{41} \mathrm{El}$ informe sobre 1997 mencionó un aumento de las violaciones de los derechos humanos cometidas por el ejército y los grupos paramilitares, brindó ejemplos sobre ejecuciones extrajudiciales y de desapariciones, y denunció la masacre de Acteal. ${ }^{42}$ El informe sobre 1998 hizo referencia a un proyecto de ley de la CNDH sobre las desapariciones forzadas. Dio también ejemplos de amenazas de muerte por el ejército y las fuerzas de seguridad, de desapariciones y ejecuciones extrajudiciales, de asesinatos de campesinos y de políticos, y narró las masacres del Bosque y del Charco. Asimismo, informó de la publicación del Libro blanco, acusando a agentes del gobierno en el caso de Acteal. ${ }^{43}$ Con el informe sobre 1999, presentó la evolución positiva del caso de Acteal, ya que tuvo lugar la imposición de varias sentencias, pero aludió también a las desapariciones, cuyo número de casos sin resolverse aparentemente disminuyó, aunque sí se descubrió una fosa común en Ciudad Juárez. ${ }^{44}$

Human Rights Watch, en su informe sobre 1996, no trató directamente del derecho a la vida, sino habló más bien de ataques en contra de va-

40 Aquí se trata de numerosos asesinatos de mujeres en esta ciudad — 193 casos en 1993 -.

41 Amnistía Internacional, Informe 1996, Londres, Amnistía Internacional, Publicaciones, 1996, p. 8.

42 Op. cit., nota 19, p. 8.

43 Op. cit., nota 20, p. 8.

44 Op. cit., nota 21, p. 8. En el caso de Ciudad Juárez, se descubrieron cadáveres de personas aparentemente ligadas al narcotráfico. 
rias personas. ${ }^{45}$ En su informe sobre 1997, comentó las desapariciones en el norte del país, vinculadas al narcotrafico. ${ }^{46}$ En el informe sobre 1998, tomó en cuenta el informe de la CNDH sobre el caso de Acteal, y denunció la pasividad de las autoridades durante el acontecimiento. ${ }^{47}$ Para terminar, el informe sobre 1999 dio ejemplos de desapariciones y relató también la condena de varias personas en el caso de Acteal. ${ }^{48}$

De esta suerte, no se puede deducir una evolución positiva del derecho a la vida en México durante el periodo estudiado. Los organismos fueron unánimes en cuanto a una evolución negativa - y con un agravamiento en 1996 y 1997, a pesar de la existencia de esfuerzos por parte de la $\mathrm{CNDH}$ - . Tal situación puede explicarse por los movimientos insurreccionales en varias partes del país, que dieron lugar — como lo subraya el CDH"FFV" - a la aparición de violaciones del derecho a la vida de manera indiscriminada, y con las varias masacres que ocurrieron en México durante esta época.

\section{Violaciones del derecho a la libertad personal}

El derecho a la libertad personal esta vinculado al comportamiento de las fuerzas de seguridad — principalmente la policía y el ejército-. La CNDH no destacó violaciones de este tipo en los anexos de sus informes. ${ }^{49}$ En el reporte del CDH“FFV", la privación ilegal y arbitraria de libertad permaneció igual que en 1997, mientras el número de desapariciones forzadas temporales aumentó con la lucha contra la guerrilla y el narcotrafico. Existieron ciertos casos de detención temporal de personas por el ejército, pero los autores sólo fueron acusados de haber cometido delitos comunes. ${ }^{50}$

La CIDH recibió denuncias durante su visita en México sobre detenciones arbitrarias. Estimó esta violación como una práctica sistemática en México, cuyos autores eran los agentes de la policía judicial federal o estatal, preventiva, etcétera. Tenía generalmente como consecuencia la violación del derecho a la integridad personal y de las garantías judiciales. Las denuncias aumentaron, según la CIDH, y recomendó al Estado mexi-

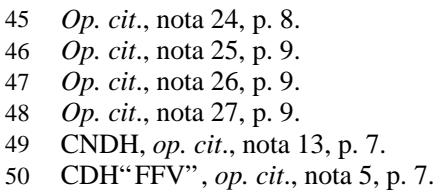


cano modificar los métodos utilizados por la policía judicial para combatir la delincuencia, con una reestructuración y una reeducación de los funcionarios de la policía. ${ }^{51}$

Los informes del alto comisionado de la ONU que elegí no comprendieron directamente este tipo de violación. En los dos primeros informes de Amnistía Internacional, la violación de la libertad personal no apareció como elemento central de la situación de los derechos humanos en México. Sin embargo, el primero cubrió y dio ejemplos de detenciones arbitrarias y de secuestros de políticos, periodistas, activistas de derechos humanos e indígenas. ${ }^{52} \mathrm{El}$ segundo no abarcó el tema. ${ }^{53}$ En el tercer informe, la detención arbitraria irrumpió como elemento central, y se analizó el problema de los presos de conciencia. ${ }^{54}$ En el cuarto informe se contenían ejemplos de detenciones arbitrarias. ${ }^{55}$

Human Rights Watch no contempló directamente violaciones de la libertad personal en su primer y segundo informe ${ }^{56} \mathrm{El}$ tercero y el cuarto informe se refirieron a la persistencia de la detención arbitraria en México. Cubrieron también el problema de los arrestos arbitrarios y ofrecieron ejemplos. ${ }^{57}$

Este problema en México ha sido estructural, porque ha tenido que ver con el funcionamiento del Estado, a través de sus fuerzas de seguridad. Aquí, aparte del CDH"FFV" — que destacó un aumento de las desapariciones forzadas temporales con la lucha contra la guerrilla y el narcotrafico, y de la CIDH - que subrayó un incremento de las denuncias, los otros organismos no observaron un ascenso de este tipo de violación, y las dos ONGs internacionales lo trataron levemente. Podría explicarse esta circunstancia por una falta de información, por una cuestión de acceso, o porque el interés de los organismos se ha concentrado en otras violaciones. De todos modos, sólo se puede advertir aquí un estancamiento de la situación en esta época.

54 Ibidem, nota 21, p. 8.

55 Ibidem, nota 23, p. 8.

56 Human..., cit., notas 24 y 25 , pp. 8 y 9, respectivamente.

57 Ibidem, notas 26 y 27 , p. 9. 


\section{Violaciones del derecho a la integridad física y psicológica}

Este tipo de derecho está directamente vinculado al problema de la tortura, que sigue siendo muy importante en México, y cuyo respeto es fundamental en un Estado de derecho. Es estructural también y se relaciona con el sistema policiaco y de seguridad del país. También esta vinculado al problema de la impunidad, un elemento central del problema del respeto de los derechos humanos en México. Aquí, el anexo del informe de 1997 de la CNDH cuenta en su lista de violaciones de los derechos humanos la intimidación y la tortura, y sus responsables parecieron ser la Procuraduría de Justicia del Distrito Federal y del Estado de Oaxaca. ${ }^{58}$ Así mismo, apareció la intimidación en el anexo del tercer informe, con la responsabilidad de la Procuraduría de Justicia del Distrito Federal. ${ }^{59}$ Los anexos de los otros informes no hicieron referencia a éste tipo de violación. ${ }^{60}$

El CDH“FFV" se pronunció por un aumento de la tortura, de los tratos crueles, inhumanos y degradantes, de las intimidaciones y de las injerencias arbitrarias e ilegales, tanto en el contexto de la lucha contra la insurrección y el narcotráfico, como para disuadir a las víctimas de abusos para denunciarlas. ${ }^{61}$

La CIDH presentó la tortura como una práctica usada por los agentes del Estado, en situaciones extrajudiciales, pero también en el caso de investigaciones judiciales, con el objetivo de intimidar a los detenidos, de auto-incriminarlos y de obtener confesiones. Subrayó la CIDH que, a pesar de la existencia de un marco legal en México, la tortura y la impunidad persistían. La CIDH recibió quejas y, según la información que consiguió, la mayoría de los casos de tortura tenían lugar durante las investigaciones realizadas con motivo de la persecución de los delitos. Así, según ella, los agentes de la policía judicial federal y estatal eran generalmente los responsables, junto con los agentes del Ministerio Público y los miembros de las fuerzas armadas. El uso de la tortura como método de investigación policiaca aumentó por el hecho de que el sistema jurídico mexicano daba en esa época una fuerza jurídica importante a la prime-

58 CNDH, Informe..., cit., 1997, nota 13.

59 Ibidem, 2000, nota 13.

60 Sin embargo, existen recomendaciones de la CNDH sobre la impunidad. Véase, ibidem, pp. 573-585.

61 CDH“FFV", op. cit., nota 5, p. 7. 
ra declaración del acusado. Así, aparecía que el hecho de darle un efecto probatorio a las declaraciones extrajudiciales, o realizadas durante la etapa de la investigación ministerial, favorecía el uso de la tortura por parte de la policía. ${ }^{62}$

El informe del relator especial sobre la tortura de enero de 1998, es un informe bastante importante, y se elaboró después de una visita de dicho relator a México del 7 al 16 de agosto de 1997, durante la cual tuvo entrevistas con representantes de las autoridades mexicanas y con víctimas de tortura en varias partes del país. ${ }^{63}$ Según fuentes no gubernamentales, la tortura seguía siendo usada en México y se empleaba generalmente durante las investigaciones de la policía judicial. Se usaba también en contra de niños de la calle, de militantes campesinos o de la oposición, y en el marco de la lucha contra la insurrección —en el estado de Guerrero, por ejemplo- El relator presentó casos y solicitó investigaciones. Aludió también a casos de tortura durante operaciones militares en el estado de Oaxaca y contra miembros de ONGs en varios estados de la república. Sin embargo, de acuerdo con las autoridades, el número de casos de tortura en México descendió por la adopción de medidas legislativas. La mayor parte de los casos de tortura tenían lugar inmediatamente después de la detención, y el problema era que la mayor parte de las quejas se entregaban a las comisiones de derechos humanos, y éstas sólo emiten recomendaciones. El relator declaró que no puede considerar la tortura como sistemática en México y subrayó una preocupación mayor en lo relativo a la imagen del país en la escena internacional. Sin embargo, destacó el uso importante de la tortura para obtener confesiones e informaciones. Los principales responsables eran los funcionarios federales o de los Estados, los agentes de la policía de prevención o judicial, y también los militares. Las principales víctimas eran personas sospechosas de cometer infracciones al derecho común o perseguidos políticos. Hizo notar también la falta de independencia de los médicos encargados de realizar los peritajes médicos. Así, el relator recomendó la creación de un sistema de inspección independiente de las cárceles y de un dispositivo de grabación en video de los interrogatorios. También recomendó el otorgamiento de valor probatorio únicamente a las declaraciones que se hagan en pre-

62 CIDH-OEA, op. cit., nota 15, p. 7.

63 Conseil Economique et Social, Rapport du Rapporteur Spécial sur la torture: visite au Mexique, 14 janvier 1998/Rapport soumis par le Rapporteur Spécial M. Nigel Rodley, en application de la Résolution 1997/38 de la Commission des droits de l'homme, E/CN.4/1998/38/Add.2. 
sencia del juez, el no regreso de las personas ya interrogadas a la guardia de la policía, el mejoramiento del sistema de defensa de oficio, la instauración de un sistema de rotación para evitar la corrupción, etcétera. ${ }^{64}$

En los informes de Amnistía Internacional, el uso de la tortura por parte de la policía y del ejército era un problema central de la cuestión de los derechos humanos en México. Lo eran también los malos tratos. En el informe de 1996 se presentaban casos de tortura de militantes políticos, periodistas, activistas de derechos humanos y de indígenas en los estados de Oaxaca, Guerrero y Chiapas, y de malos tratos en las cárceles. ${ }^{65}$ En el segundo, se hablaba de la primera visita a México del relator especial de Naciones Unidas sobre la Tortura. Este aludió a los malos tratos de que eran víctimas los niños de la calle. ${ }^{66} \mathrm{El}$ tercero contemplaba casos de tortura y de amenazas de muerte por parte del ejército. ${ }^{67}$ El último abordaba la tortura en Chiapas y ofreció ejemplos de malos tratos en la cárcel de Apodaca en Nuevo León, caso sobre el cual la CNDH emitió recomendaciones que no tuvieron efectos. ${ }^{68}$

Human Rights Watch, en su informe sobre 1996, habló también de casos de tortura. Se refirió igualmente a la impunidad de los agentes públicos, autores de torturas durante la detención de miembros del EZLN en 1995, y de la ausencia de sanciones en general a oficiales de policía, militares u oficiales públicos responsables de tortura. Subrayó el problema de la "justicia inmediata", que daba más peso a la primera confesión del acusado, y que tenía como consecuencia el uso de la tortura. También, si los autores resultaban condenados, sólo era por abuso de poder, como en el caso del problema con los zapatistas de Yanga. ${ }^{69}$ En el informe sobre 1997, se trató del uso de la tortura contra miembros del EPR y en el marco de la lucha contra el narcotráfico. ${ }^{70} \mathrm{El}$ informe sobre 1998 mencionó la persistencia de la tortura — que apareció dentro del grupo de violaciones más frecuentes- y del informe del relator especial de Naciones Unidas sobre la Tortura. ${ }^{71}$ En el informe sobre 1999, se afirmó que persistía éste

64 Con la adopción ulterior de leyes sobre tortura en México, se aceptaron ciertas de éstas recomendaciones.

65 Amnistía..., cit., nota 41, p. 8.

66 Ibidem, nota 19, p. 8.

67 Ibidem, nota 20, p. 8.

68 Ibidem, nota 21, p. 8.

69 Human..., cit., nota 24, p. 8.

$70 \quad$ Ibidem, nota 25, p. 9.

71 Ibidem, nota 26, p. 9. 
delito. Se trató también la tortura en el marco de persecuciones criminales, y se dieron ejemplos. ${ }^{72}$

La lectura de estos informes permite pensar que siguió siendo usada la tortura en México con una preocupante frecuencia durante el periodo estudiado. Pero lo interesante aquí, en cuanto a este estudio, es que se contradijeron las conclusiones de los diferentes organismos. Las ONGs y la CIDH hablaron de una persistencia o de un aumento del uso de la tortura en México, cuando el informe del relator especial de la ONU sostuvo que no podía considerarse la tortura como sistemática en México, y subrayó que las declaraciones del gobierno mexicano hablaban de una disminución de los casos de tortura por la adopción de medidas legislativas. $^{73}$

\section{Violaciones del derecho a la libertad de opinión, de expresión $y$ de información}

Dentro de los diez primeros tipos de quejas recibidas por la CNDH, no apareció ninguna en relación con la violación de este derecho. ${ }^{74}$ En el informe del CDH "FFV", apareció como un tema que tomó importancia en México durante los años precedentes, y que estuvo analizado en varios foros y conferencias, durante las cuales, en la mayoría de los casos, se presentó como un derecho de los trabajadores y de los medios de comunicación, una necesidad para el respeto de la libertad de expresión y la libre manifestación de las ideas. Destacó aquí el CDH "FFV" un aumento del hostigamiento contra los medios de información. ${ }^{75}$

$\mathrm{La} \mathrm{CIDH}^{76}$ reconoció un refuerzo y un mejoramiento de la prensa libre y crítica en México, a pesar de que las denuncias de violencias cometidas contra periodistas habían aumentado. Dio ejemplos de violaciones,

72 Ibidem, nota 27, p. 9.

73 Eso se podría explicar por el hecho de que el relator de Naciones Unidas analiza casos extremos en el mundo, como los de Ruanda, Sierra Leona, Ex Yugoslavia, etcétera.

74 Sin embargo, existen programas de la CNDH relativos a este derecho. El informe sobre 1999, por ejemplo, contiene un Programa de Atención de Agravios a Periodistas y Defensores Civiles de Derechos Humanos. Véase CNDH, op. cit., nota 13, 2000, pp. 601-603.

75 CDH“FFV", op. cit., nota 5, p. 7.

76 La CIDH creó un relator sobre la libertad de expresión en 1997. Analiza casos particulares, hace visitas in loco, y publica informes generales y especiales. Expresó su preocupación en cuanto a México, por ser uno de los países en América Latina donde la situación de este derecho es la más grave. Recibió numerosas denuncias de actos graves de violación de los derechos de los periodistas, de los defensores de los derechos humanos y de los miembros de organizaciones sociales. 
recomendó la revisión de los artículos 6o. y 7o. de la Constitución, la adopción de medidas para sancionar estas violaciones, y la protección del trabajo de los defensores de los derechos humanos. ${ }^{77}$

La ONU presentó casos de secuestros y detenciones de periodistas en un informe de $1998 .{ }^{78}$ Amnistía Internacional no abordó este derecho como un elemento central. En el informe sobre 1996, presentó casos de amenazas, secuestros y tortura de periodistas. ${ }^{79}$ En el informe de 1997, relató el caso de la detención de un periodista. ${ }^{80} \mathrm{El}$ informe de 1998 no consideró directamente el problema, y tampoco el de 1999. ${ }^{81}$

Human Rights Watch trató ataques de periodistas en su primer informe. ${ }^{82}$ En el segundo, refirió un aumento de los periodistas víctimas de hostigamiento, de ataques físicos, y hasta de asesinatos — dos casos — ${ }^{83}$ el tercero también, así como de presiones por parte del gobierno. ${ }^{84}$ Por fin, el último no abordó el problema.

El derecho a la libertad de opinión, de expresión y de información, por la pobreza de la información que apareció sobre él, parecía quedarse un poco hacia atrás de la atención de los organismos en comparación con los otros derechos ya analizados. Se puede pensar que conoció este tipo de derecho una evolución positiva en esta época con el desarrollo de la prensa libre y crítica. Sin embargo, según el informe del CDH“FFV”, aumentó el hostigamiento de los medios de información, lo que traduce una persistencia de la fragilidad de un "cuarto poder" mexicano que se estaba todavía emancipando de los controles del Estado.

\section{Violaciones de los derechos políticos}

Este tipo de derechos es fundamental en el marco del tema de la democracia. Representa uno de los temas más importantes en México, por el proceso de transición política vivido por el país, y fue objeto de una atención particular por los organismos estudiados. La CNDH no presentó

78 Rapport du Rapporteur Spécial sur la promotion et la protection du droit à la liberté d'opinion et d'expression, Conseil Economique et Social, 28 janvier 1998, E/CN.4/1998/40.

79 Amnistía..., cit., nota 41, p. 7.

80 Ibidem, nota 19, p. 8.

81 Ibidem, nota 20 , p. 8.

82 Human..., cit., nota 24, p. 8.

83 Ibidem, nota 25, p. 9.

84 Ibidem, nota 26, p. 9. 
quejas relativas a este problema en los anexos de sus informes. ${ }^{85} \mathrm{El}$ informe del CDH"FFV" le dedicó una parte importante, empezando con el carácter dominante de temas como la transición a la democracia, el ejercicio de los poderes políticos, la limitación del poder presidencial, el diálogo entre los partidos políticos y la reforma del Estado durante el periodo estudiado. Relató un mejoramiento del sistema democrático mexicano por el aumento de la competencia entre los partidos y la alternancia en el poder en ciertos estados de la república, en el marco de los cuales el PRI aceptó casi todos los resultados. El presidente dejó de ser el "gran elector". Las elecciones libres se consolidaron y estuvieron en camino para convertirse en un derecho adquirido en la realidad. Sin embargo, siguieron la limitación de la libre circulación, del derecho de reunión y de asociación pacífica. También siguieron violándose los derechos políticos de los pueblos indígenas, por no poder usar sus costumbres ni nombrar a sus propios representantes. ${ }^{86}$

La CIDH argumentó que la mayoría de las denuncias que recibió en cuanto a este derecho correspondieron a irregularidades en el nivel electoral. Emitió recomendaciones y destacó en ellas un progreso relativo al fortalecimiento y la independencia del Instituto Federal Electoral (IFE), ${ }^{87}$ y también a las elecciones de julio de 1997, que se consideraron como regulares. Dio ejemplos de violaciones de los derechos políticos, pero habló de mejoramiento. Mencionó igualmente el consenso político respecto a las reformas políticas y el avance de la autonomía y de la independencia de los órganos electorales, una competencia electoral más justa, un mejor control de los recursos aplicables al financiamiento de los partidos políticos, un acceso más equitativo de los partidos a los medios de comunicación. Los problemas que persistían eran: tensiones locales, el peso del caudillismo sobre el voto de los electores, etcétera. En cuanto a las reformas, se introdujo la credencial con fotografía en 1992 y aumentó el número de casillas. El problema que persistió fue la falta de definición de los delitos electorales. De los avances en materia de consenso entre

85 Eso se puede explicar por la existencia del Instituto Federal Electoral, que tiene competencia para los asuntos vinculados con el proceso electoral en México.

86 CDH"FFV", op. cit., nota 5, p. 7.

87 El IFE se creó con la reforma constitucional de 1990, y se reformó en 1993, 1994 y 1996. Es el órgano electoral del Estado mexicano (con un consejo general y un consejero presidente, ocho consejeros electorales, consejos del Poder Legislativo, representantes de partidos políticos y un secretario ejecutivo). Sus tres principales misiones son: la dirección, la ejecución y la supervisión de las elecciones. 
partidos, se destacaron la incorporación del Tribunal del Instituto Federal Electoral (TRIFE) al Poder Judicial Federal, el establecimiento de mecanismos de supervisión y de disciplina del TRIFE, etcétera. Los cambios más importantes tuvieron lugar entonces a partir de 1997. Hubo también reformas significativas en materia de financiamiento de campañas y de acceso a los medios de comunicación, con la limitación de las contribuciones individuales, la inclusión de un límite en cuanto a las donaciones anónimas, la determinación de un límite en los gastos de campaña, y el establecimiento, en 1996, de un tiempo para la utilización de los medios de comunicación más importantes. Para concluir, la CIDH recomendó la adopción de medidas para que el derecho de votar y de ser elegido permita un acceso más amplio y más participativo de los candidatos en el proceso electoral; la definición clara de los delitos electorales y el establecimiento de mecanismos que permitan sancionarlos; y, por ultimo, la creación de una reglamentación clara en cuanto a los fondos financieros de los partidos políticos. ${ }^{88}$

No tenemos informes de la Organización de Naciones Unidas sobre el tema. En el caso de Amnistía Internacional, el primer informe no lo trató tampoco. El segundo subrayó la perdida de la mayoría de la cámara de los diputados por parte del PRI y la elección del PRD para encabezar el gobierno del Distrito Federal en julio de $1997 .{ }^{89}$ El tercer y cuarto informes no consideraron este punto.

Human Rights Watch tampoco lo contempló en su primer informe, pero subrayó en el segundo los avances significativos en materia de derechos políticos, con las elecciones de julio de $1997 .{ }^{90} \mathrm{El}$ problema no apareció en los informes tercero y cuarto.

La lectura de estos informes ofrece una mejoría cierta del respeto de los derechos políticos en México durante el periodo estudiado, lo que constituye el primer avance positivo en el marco de este análisis. Varios acontecimientos marcaron tal evolución: las elecciones de julio de 1997, así como el refuerzo y la independencia del Instituto Federal Electoral, por ejemplo. Aquí, todos los organismos estuvieron de acuerdo en subrayar lo positivo de los avances de la materia en México - a pesar de que seguían ciertos problemas, tales como la falta de definición de los delitos 
electorales-. Se confirmó después este proceso con las elecciones presidenciales de julio 2000, que dieron la victoria a un partido de oposición de manera democrática por primera vez en México después de 71 años de presencia en el poder del PRI como partido oficial.

\section{Violaciones del derecho a la seguridad jurídica}

Este tipo de derecho está vinculado al funcionamiento del sistema judicial, y también al tema importante en México de la impunidad. La $\mathrm{CNDH}$, en cuanto a este derecho, tuvo quejas en los anexos de su primer informe, que estuvieron vinculadas al incumplimiento de recomendaciones, sentencias o laudos, a retrasos en la procuración de justicia y a la falta de fundamento o de motivación legal. Las autoridades supuestamente responsables no se pudieron determinar. ${ }^{11}$ En su segundo informe, aparecieron también el incumplimiento de recomendaciones, sentencias o laudos y la falta de fundamento o de motivación legal..$^{92}$ En su tercer informe aparecieron quejas relativas a la exigencia para realizar un acto o una omisión sin fundamento legal. ${ }^{93}$

El CDH"FFV" trató en su informe la falta de garantías en cuanto a la seguridad de los acusados de delitos. Destacó varios elementos que denunciaban que la procuración de justicia se encontraba viciada por intereses políticos y económicos. El organismo manifestó también que la corrupción de las corporaciones de seguridad y de la procuración de justicia aparecía como un fenómeno, cuyas causas no se podían explicar únicamente por la irresponsabilidad personal. La tortura siguió siendo usada como método privilegiado en todos los niveles de investigación, y muchos ejemplos condujeron a cuestionar la administración y la procuración de justicia en México. Según los informes públicos, el consejo sancionó a varios jueces que habían cometido errores, y "sometió a proceso legal" a dos de ellos por tales motivos. Sin embargo, afirmó que la situación prevaleciente en el Poder Judicial era muy grave.

La CIDH planteó el problema en un capítulo sobre el derecho a la justicia. ${ }^{94}$ Trató la cuestión de la impunidad, que calificó de problema grave en México, y en el marco del cual estimó que el trabajo de la $\mathrm{CNDH}$ era importante. Consideró que la impunidad era un "cáncer so-

93 Ibidem, 1999, p. 14.

94 CIDH-OEA, op. cit., nota 15, p. 7. 
cial", que provocaba una desconfianza respecto a las autoridades y favorecía la delincuencia. Mencionó la CIDH también una situación de incertidumbre jurídica por la inacción del Ministerio Público. Habló de la necesidad de reforzar la independencia, la autonomía y la imparcialidad de éste en numerosos casos, ya que constituye un monopolio de la acción penal y depende del Poder Ejecutivo. La CIDH recomendó una revisión de la ley general que establecía las bases de la coordinación del sistema de seguridad pública. Propuso también reformas que permitirían la limitación de las facultades del Ministerio Público. En cuanto a la policía judicial, la CIDH recibió testimonios alarmantes sobre la corrupción, los abusos y los desacuerdos que existían entre las diferentes policías del país. Trató también el problema de la formación limitada del personal y de los salarios bajos. Presentó el problema de la falta de independencia, de la parcialidad, de la corrupción y de la falta de prestigio de los jueces en el nivel de la opinión pública. Recomendó entonces el refuerzo de la independencia y de la autonomía del Ministerio Público, la revisión de la naturaleza jurídica y de la competencia de la Unidad de Coordinación de la Seguridad Pública de la Nación, la limitación de las competencias del Ministerio Público y de la Policía Judicial, la mejoría de las condiciones de trabajo, de la preparación y de la remuneración de los funcionarios del Ministerio Público y de la Policía Judicial, etcétera.

La ONU trató este problema en el marco de un informe de 1998 sobre la independencia de los jueces y de los abogados. En este informe, solamente presentó dos casos de amenaza en contra de un miembro de la Asociación Nacional de los Abogados Democráticos y en contra del presidente del Tribunal Superior del Estado de Tabasco. ${ }^{95}$ Amnistía Internacional no presentó las violaciones de este derecho como elemento central de sus informes y no lo trató directamente. Los informes de Human Rights Watch tampoco lo consideraron.

El derecho a la seguridad jurídica está relacionado con un sistema jurídico que siguió presentando varios problemas en México durante el periodo estudiado - la impunidad, la desconfianza sobre los jueces, la lentitud del sistema, etcétera-, y que aparecieron como persistentes en la lectura de los varios informes estudiados.

95 Rapport du Rapporteur Spécial sur l'indépendance des juges et des avocats, Conseil Economique et Social, 12 février 1998, E/CN.4/1998/39. 


\section{Violaciones de los derechos de la mujer}

La CNDH no presentó quejas relativas a este derecho, aunque tiene un programa permanente sobre éste tema. ${ }^{96} \mathrm{El} \mathrm{CDH"FFV"} \mathrm{y} \mathrm{la} \mathrm{CIDH} \mathrm{no}$ lo consideraron tampoco en sus informes. La ONU le dedicó dos informes. El primero era relativo a las prácticas que afectan la salud de las mujeres y de las niñas. ${ }^{97}$ Sobresalió la existencia en México de tales prácticas, que influyan en el respeto de los derechos de la mujer. Insistió en la necesidad de luchar contra este tipo de violencia, y llamó la atención sobre la creación en 1989 de centros para las víctimas de la violencia familiar, para las personas perdidas y para los menores víctimas de delitos. Contra este tipo de violencia, se adoptaron medidas legislativas y administrativas, y el Senado mexicano ratificó la Convención Interamericana para la Prevención, el Castigo y la Erradicación de la Violencia contra la Mujer. Se creó también un Programa Nacional para la Mujer, en vigor entre 1995 y 2000, que se llama Alianza por la Igualdad. En el segundo informe, se trató el problema de la violencia contra las trabajadoras migrantes, ${ }^{98}$ que era una preocupación prioritaria del gobierno mexicano durante el periodo estudiado. Estas mujeres sufrían malos tratos, intimidaciones, amenazas y abuso sexual. También sufrían privaciones de alimentos, confiscación de papeles y de artículos personales, insultos con carácter racial, etcétera. Amnistía Internacional y Human Rights Watch no trataron directamente el problema en sus informes generales.

Los derechos de la mujer son importantes en una sociedad como la mexicana, ya que existe en el país una tendencia en la discriminación de la mujer respeto al hombre. ${ }^{99}$ Sin embargo, no aparecieron de manera importante en los informes de los organismos estudiados. Sólo se puede concluir en este punto la existencia de iniciativas por parte del gobierno mexicano durante el periodo estudiado para mejorar el respeto de este tipo de derecho, lo que ya es algo positivo.

96 Véase, por ejemplo, el Programa sobre Asuntos de la Mujer, el Niño y la Familia del Informe sobre 1999. CNDH, op. cit., 2000, nota 13, pp. 588-601.

97 Deuxième rapport sur l'évolution de la situation concernant l'élimination des pratiques traditionnelles affectant la santé des femmes et des fillettes, Conseil Economique et Social, 26 juin 1998, E/CN.4/Sub.2/1998/11.

98 Rapport du Secrétaire Général sur la violence à l'égard des travailleuses migrantes, Conseil Economique et Social, 26 décembre 1997, E/CN.4/1998/74.

99 Por ejemplo, en el nivel laboral. 


\section{Violaciones de los derechos de los pueblos indígenas}

Estos derechos son de gran importancia en México, donde los pueblos indígenas representan diez millones de personas —es decir el diez por ciento de la población total-, donde existen 20000 localidades indígenas, y donde algunos de estos pueblos se encuentran involucrados en una situación de guerrilla, notoriamente desde 1994, con el levantamiento del EZLN. La CNDH, aunque tenga un programa de atención sobre éste tema, no hizo referencia a este tipo de violaciones en las partes de sus anexos analizados. ${ }^{100} \mathrm{El} \mathrm{CDH“FFV"} \mathrm{planteó} \mathrm{que,} \mathrm{durante} \mathrm{el} \mathrm{periodo} \mathrm{ana-}$ lizado, el gobierno mexicano siguió con su intento de reducir la complejidad de la situación de los pueblos indígenas al problema de cuatro municipios del estado de Chiapas, aunque era evidente que la situación de marginalidad y de pobreza no se manifestó únicamente en el sur del país. ${ }^{101}$

La CIDH presentó la situación de los pueblos indígenas en México. Trató el reconocimiento de la pluralidad de la composición de la población mexicana en la Constitución y de las costumbres indígenas en la ley, con límites. Mencionó también la influencia de los pueblos indígenas en el proceso electoral y varios incidentes en el momento del voto, que motivaron desconfianza en cuanto a las elecciones. La CIDH sostuvo que existía un proceso de militarización de las zonas indígenas del país durante los últimos años. Las violaciones asociadas a éste proceso eran la restricción de la libertad de circulación y de comercio, la violación del derecho a la vida, a la integridad física, de la libertad y de la propiedad. Aumentaron las agresiones y las violaciones cometidas por militares y agentes de la policía contra las mujeres indígenas de los campos. La CIDH trató el caso particular de los indígenas del estado de Oaxaca, cuya presencia era muy importante, y donde se desarrolló la presencia de las fuerzas armadas con el objeto de impedir una expansión del movimiento zapatista hacía el norte del país y de resistir a las acciones del Ejército Popular Revolucionario (EPR). En éste marco, tuvieron lugar ejecuciones y detenciones arbitrarias, actos de tortura, y ataques contra la población civil por parte de las fuerzas oficiales. ${ }^{102}$

100 Tiene, sin embargo, la CNDH un Programa de Asuntos Indígenas. Véase CNDH, op. cit., 2000, nota 13, pp. 585-588.

101 CDH“FFV”, op. cit., nota 5, p. 7.

102 CIDH-OEA, op. cit., nota 15, p. 7. 
La ONU, en el informe de la Subcomisión para la Lucha contra las Medidas Discriminatorias y para la Protección de las Minorías de 1998, afirmó su preocupación por la situación de los pueblos indígenas en México - y sobre todo en Chiapas-. Pidió a las autoridades mexicanas el respeto de los instrumentos internacionales, y la lucha contra la impunidad de los autores de violaciones graves de los derechos humanos de las poblaciones autóctonas. ${ }^{103}$

En los informes de Amnistía Internacional, los derechos de los pueblos indígenas no aparecieron dentro de los principales problemas vinculados a los derechos humanos en México. El informe sobre 1996, habló de actos de tortura y de amenazas contra indígenas de Oaxaca, Guerrero y Chiapas. ${ }^{104}$ El informe sobre 1997 trató violaciones de los derechos de los indígenas. ${ }^{105} \mathrm{El}$ informe sobre 1998 no analizó directamente el problema, y tampoco el informe de 1999. ${ }^{106}$ Human Rights Watch, en sus cuatro informes, no se refirió a tales derechos. ${ }^{107}$

Aparecieron entonces las violaciones de los derechos de los pueblos indígenas como preocupantes para los organismos estudiados, aunque sólo los consideraron particularmente la CNDH y la CIDH. No se puede entonces realmente sacar conclusiones concretas de la lectura de los informes, mientras sabemos, sin embargo, que la situación de los pueblos indígenas en México es de lo más problemático y de lo más grave. En este caso entonces - que trata derechos colectivos- la información es menos importante que la relativa a las violaciones de los derechos individuales analizados. El tema debió de haber sido más importante para los observadores.

\section{Violaciones de los derechos económicos, culturales y sociales}

La CNDH no presentó quejas en sus anexos, que se refieren específicamente a este tipo de derechos. El CDH"FFV" siguió en línea semejante. La CIDH les dedicó un capítulo de su informe. Enfatizó el problema de la distribución de la riqueza en México. Las cifras del PNUD y del

103 La situation au Mexique et son évolution, Résolution de la Sous-Commission pour la lutte contre les mesures discriminatoires et la protection des minorités 1998/4, Conseil Economique et Social, 20 août 1998, réf. E/CN.4/SUB.2/RES/1998/4.

104 Amnistía..., cit., nota 41, p. 8.

105 Ibidem, nota 19, p. 9.

106 Ibidem, notas 20 y 21, p. 9.

107 Human..., cit., notas 24-27. 
Banco Mundial, según ella, eran alarmantes, y la situación en México era particularmente crítica desde el año 1995, cuando la instauración de medidas de emergencia económica y del programa de ajuste estructural propiciaron un incremento notable de dificultades y carencias. ${ }^{108}$ Sin embargo, señalo que aumentó el número de instituciones de educación primaria y superior desde 1970, así como los gastos públicos correspondientes. A pesar de ello, la crisis afectó el sector de la salud y hubo un deterioro de los salarios desde los años ochenta. México ratificó en 1996 el Protocolo Adicional de la Convención Americana sobre los Derechos Humanos en Materia de Derechos Económicos, Sociales y Culturales, y el gobierno propuso varias acciones para mejorar su situación: disminuir la tasa de fecundidad, mejorar la educación, combatir la desnutrición y la mortalidad por infecciones, crear oportunidades de empleos productivos, y mejorar las condiciones de vida a través de la cultura y del deporte. Así, al constatar la situación, la CIDH recomendó al gobierno mexicano aumentar la inversión en el sector de la salud y de la educación, expandir los servicios básicos en cuanto a las infraestructuras domésticas y los servicios públicos rudimentarios (agua potable, instalaciones eléctricas, servicios sanitarios) a todos los sectores urbanos. ${ }^{109}$ La ONU no trató estos derechos en los informes que analicé. Amnistía Internacional y Human Rights Watch tampoco les trataron.

La CIDH es entonces el único organismo que consideró estos derechos. Lo hizo de manera crítica, pero también subrayó varias acciones del gobierno mexicano para mejorar la situación.

\section{CONCLUSIONES GENERALES RELATIVAS}

\section{A LA POSTURA DE LOS ORGANISMOS}

$\mathrm{El}$ análisis de los informes permite sacar varias conclusiones en cuanto a la influencia de las características y de los métodos de trabajo de los organismos estudiados. Primero, hay que subrayar que los derechos individuales tuvieron la prioridad sobre los derechos colectivos. Esto se puede explicar por la naturaleza de los organismos, pero también por la capacidad de investigación que tienen. La investigación de derechos individuales tiene la ventaja de basarse en cifras y casos bien determina-

108 La exposición de la CIDH sobre los derechos económicos, culturales y sociales en México está basada en los informes anuales del PNUD sobre el desarrollo humano.

109 CIDH-OEA, op. cit., nota 15, p. 7. 
dos, cuando la investigación de violaciones de derechos colectivos es más complicada porque son mucho más difíciles de determinar. También, en el caso de las ONGs o de la CNDH, los informes están basados en general en la recepción de quejas individuales.

En cuanto a la objetividad de los informes, la variación entre las diferentes observaciones no es tan importante como se podría imaginar. Varias veces observé que los organismos coinciden en sus conclusiones. Aparte de eso, si la información que logré tener de la CNDH es limitada en comparación con la de otros organismos — porque su trabajo es la atención de los casos particulares, y además de las recomendaciones y de sus programas, brinda asesoría y desarrolla labores de conciliación- usualmente ellos se refieren al trabajo de la comisión y le dan importancia en la defensa de los derechos humanos. La objetividad de los informes presenta variaciones ligeras en función de los organismos, pero de manera general refleja la misma situación en cuanto a los derechos humanos en México.

Las variaciones provienen de la naturaleza del organismo, de su enfoque y de su metodología de trabajo. En el caso de la CNDH, la publicación de información sobre recepción de quejas no permite una idea confiable de la situación de los derechos a los cuales se refiere, porque mucha gente no se presenta a la comisión en caso de violación o acude a ella para plantear cuestiones que no son de su competencia. ${ }^{110}$ En el caso

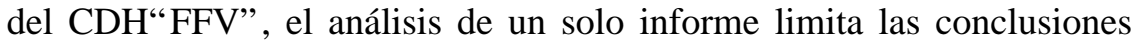
que se pueden sacar. Lo mismo ocurre en el caso de la CIDH. Sin embargo, estos dos informes son los más completos de todos y reflejan un trabajo de investigación encomiable. En el caso de la ONU, tampoco se pudo lograr tener una idea homogénea de la evolución de la situación de los derechos humanos en México, por el carácter específico de cada informe. Sin embargo, apareció una divergencia entre este organismo y los otros en cuanto a la cuestión del derecho a la integridad física y psicológica. En cuanto a Amnistía Internacional y Human Rights Watch, los dos organismos son bastante parecidos en sus características y en su trabajo. Reflejan la postura clásica de la sociedad civil internacional, que es en general bastante crítica frente al Estado. Pero, la información que suministran es bastante detallada y demuestra una voluntad de objetividad, sobre todo me parece en el caso de Human Rights Watch.

110 Sin embargo, hay que notar que el número de quejas bajó entre 1996 y 2000. La CNDH recibió 8,509 quejas en 1996, 6,523 quejas en 1998, y 6,420 quejas en 1999. 


\section{CONCLUSIONES GENERALES RELATIVAS A LA EVOLUCIÓN}

DE LOS DERECHOS HUMANOS EN MÉXICO ENTRE 1996 Y 2000

En cuanto al derecho a defender los derechos humanos, se mezclaron durante la época estudiada el aumento de la atención de la comunidad internacional con una situación de apertura lenta del gobierno mexicano. No obstante, siguieron las violaciones de este derecho en México de manera constante. El derecho a la vida en México sufrió episodios bastante negativos. En el marco del derecho a la libertad personal, destacó un aumento de las desapariciones forzadas en virtud de la lucha contra la guerrilla y el narcotráfico, y un aumento de las denuncias. Pero, por los otros informes, se concluye que hay estabilidad de la situación. En cuanto a la tortura, el problema siguió persistiendo, a pesar de la existencia de contradicciones entre los informes. La situación del derecho a la libertad de opinión, de expresión y de información, a pesar de haberse quedado un poco atrás de la atención de los organismos, parece haber conocido de manera general una evolución positiva con el desarrollo de la prensa libre y crítica. Pero, sin ninguna duda, los derechos que conocieron una evolución realmente positiva en México durante el periodo estudiado son los derechos políticos. Como ya lo había subrayado, varios acontecimientos, tales como las elecciones de julio de 1997, o el fortalecimiento y la independencia del Instituto Federal Electoral, marcaron tal desarrollo, el cual se confirmó con las elecciones de julio de 2000. No hubo cambios en cuanto al derecho a la seguridad jurídica, pero en lo tocante a los derechos de la mujer, apareció una mayor atención estatal en cuanto a la adopción de políticas públicas. En el marco de los derechos de los pueblos indígenas, la evolución de la situación no fue realmente importante y muchos problemas persistieron, lo que se verificó también con los derechos económicos, culturales y sociales, que siguieron condicionados por la situación económica del país, con dificultades agudas desde la crisis económica de 1994.

Del análisis individual de la evolución de cada uno de estos derechos, se puede concluir lo siguiente: tres de los tipos de derechos analizados conocieron una evolución positiva —el derecho a la libertad de opinión, de expresión y de información, los derechos políticos, y los derechos de la mujer; la situación de cuatro tipos de derechos no cambió- la del derecho a la seguridad pública, la de los derechos de los pueblos indígenas, la de los derechos económicos, culturales y sociales, y la del derecho a 
defender los derechos humanos; tres tipos de derechos conocieron una evolución negativa — el derecho a la vida, el derecho a la libertad personal, y el derecho a la integridad física y psicológica-.

De esta comprobación, se destaca que el problema más grave en México en cuanto a los derechos humanos y durante el periodo estudiado radicó en la violencia por parte de las fuerzas de seguridad — la policía y el ejército- y en la impunidad, y eso se encontró además agravado por las situaciones de guerrilla que ha conocido el país desde 1994. En cuanto a los otros derechos, se puede sin embargo concluir que existió una evolución bastante favorable, aunque no fue tan marcada. Todavía falta una reforma del Estado que permita erradicar problemas graves, vinculados, por ejemplo, a la violación de derechos fundamentales como los derechos de los pueblos indígenas, y que son cada vez más importantes en la vida política mexicana y para la gobernabilidad del país. 